\title{
Norois
}

Environnement, aménagement, société

226 | 2013

Commerce et développement local, déplacements urbains, valorisations agricoles, découpages

électoraux

\section{L'agriculture en Charente au XXe siècle : guide et jalons pour la recherche}

\author{
Jean Renard
}

\section{(2) OpenEdition \\ Journals}

\section{Édition électronique}

URL : http://journals.openedition.org/norois/4622

DOI : $10.4000 /$ norois. 4622

ISBN : 978-2-7535-2287-9

ISSN : $1760-8546$

Éditeur

Presses universitaires de Rennes

\section{Édition imprimée}

Date de publication : 30 mars 2013

Pagination : 109-110

ISBN : 978-2-7535-2285-5

ISSN : 0029-182X

Référence électronique

Jean Renard, "L'agriculture en Charente au XXe siècle : guide et jalons pour la recherche », Norois [En ligne], 226 | 2013, mis en ligne le 30 mars 2013, consulté le 23 septembre 2020. URL : http:// journals.openedition.org/norois/4622 ; DOI : https://doi.org/10.4000/norois.4622 
à juste titre consacrées à la guerre de 1914-1918. Pour la période suivante, la tradition est rappelée par les métiers du village, la basse-cour, et aussi par le maintien des campagnes chrétiennes, mais la pratique religieuse n'est pas la même partout comme l'aurait montré une carte du chanoine Boulard. Le changement est représenté par l'électricité et les mouvements sociaux par les grèves de 36 . La guerre 39-45 retient à bon droit la moitié des pages : les prisonniers, la terre point d'appui de l'État français, mais aussi le STO, l'accueil des réfugiés, la résistance.

La période de 1946 à 1970 fait sa place aux aspects de la société paysanne destinés à s'estomper comme le jour du cochon, la chasse, mais cela aurait gagné à être regroupé. Le changement, c'est en suivant les titres l'arrivée du tracteur, le remembrement, le passage à la banque, barrages et barricades (sans oublier la sous-préfecture de Morlaix), de la mécanisation à la motorisation, un bétail performant, la vie moderne et la promotion de la femme. Tout cela a été préparé par « une jeunesse militante », celle de la JAC et de la JACF (Jeunesse Agricole Catholique/ Féminine), qui fait l'objet de la double-page 58-59 et l'épilogue est confié à Michel Debatisse (p. 77). Suivent des textes, souvenirs ou études, qui terminent le volume (p. 78-103).

Mais le rôle tenu par les anciens de la JAC/F n'est pas dégagé, en particulier à travers le CNJA, ce qui aboutit aux lois d'orientation de 1960 et 1962 qui ne sont pas signalées. D'autre part, si deux pages de textes sont consacrées à la révolution fourragère, explicitée par ses promoteurs René Dumont et Pierre Chazal (p. 97) et à travers la description d'exploitations (p. 98), le terme et les suites n'apparaissent pas sous le titre un bétail performant. Un simple commentaire de la photo p. 71 aurait montré l'entrée d'une stabulation libre et le renouvellement du troupeau, ici avec la race pie-noire. Les différenciations dans la mise en œuvre de l'intensification laitière sont à la base des inégalités territoriales qui ne sont pas évoquées. Qu'on nous permette enfin une suggestion de vocabulaire. Je propose qu'on ajoute issus de la paysannerie à chefs d'exploitation pour ceux qui ont accompli la mutation, afin de les distinguer de ceux restés proches des paysans d'hier et de ceux qui pratiquaient dès l'avant-guerre la grande culture.

Le livre se termine par une chronologie, des tableaux statistiques synthétiques et une bibliographie. Ce beau livre « à feuilleter et à manier en famille » sait aussi répondre aux exigences habituelles des publications scientifiques, ce qui n'est pas toujours le cas.

Jean-Pierre Houssel

\section{Michel Coutelle (coord.), 2012. L'agriculture en Charente au XXe siècle : guide et jalons pour la recherche, La Crêche, Geste-Éditions/Fondation Xavier Bernard, 480 p.}

L'Association pour l'histoire de l'agriculture en France au $\mathrm{xx}^{\mathrm{e}}$ siècle, émanation de l'Académie d'agriculture de France, créée en 1995 à l'initiative de l'ancien ministre Michel Cointat, s'est lancée, avec l'aide financière de la fondation Xavier Bernard, dans la publication pour chaque département français d'un guide de recherche à destination des chercheurs.

Le projet consiste à décrire les sources relatives à l'histoire agricole de chaque département, de dresser la bibliographie la plus complète possible sur le sujet et de présenter des témoignages d'acteurs ayant participé au développement agricole ou encore de revenir sur les évolutions des productions emblématiques des territoires ou sur les organismes qui ont œuvré dans le département pour l'agriculture.

Le volume sur la Charente est le troisième de la collection, après la Vienne en 2001 et les DeuxSèvres en 2006. L'ambition est de couvrir tout le territoire. C'est Michel Coutelle, ancien directeur de la chambre régionale d'agriculture Poitou-Charentes qui a coordonné l'ouvrage avec une dizaine de collaborateurs, praticiens, géographes et sociologues.

Les différents chapitres son organisés en fonction de ce qui fait l'originalité agricole de chaque département. Ainsi, dans ce volume sur la Charente, 


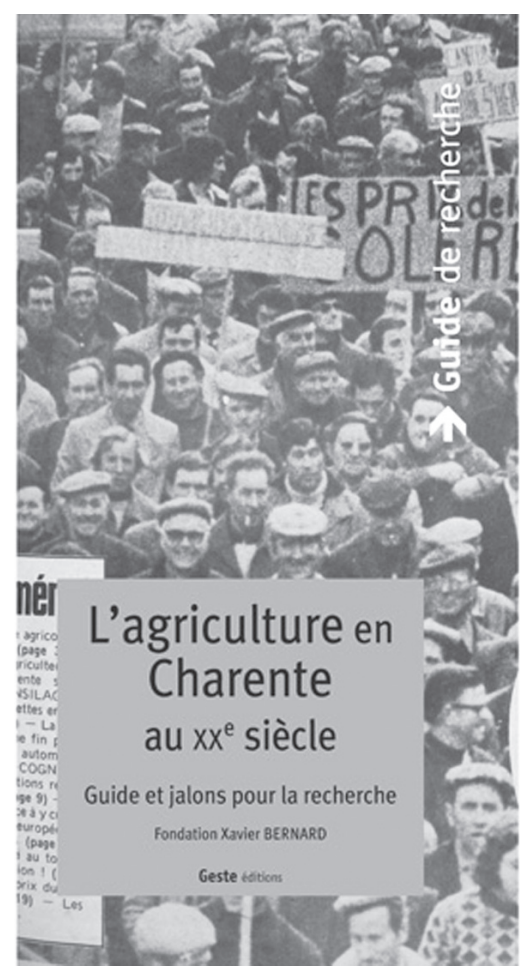

après une présentation des paysages et des principales spéculations agricoles du département, est rappelée à grands traits l'histoire de l'agriculture depuis les débuts du XIX ${ }^{e}$ siècle. Un long chapitre est consacré au cognac, notamment aux maisons de négoce et au conservatoire du vignoble charentais.

Puis est rappelé, dans ce département saigné par l'exode rural, l'importance des migrations depuis les départements de l'Ouest, et le rôle novateur joué par ces agriculteurs venus d'ailleurs. Les principales structures responsables du développement agricole au long du siècle sont successivement présentées : syndicalisme, administration, organismes de vulgarisation, de développement et de formation, presse, responsables agricoles, notamment les ministres charentais de l'agriculture ( Maurice Raynaud, Jean Hennessy, Félix Gaillard)

L'originalité de l'ouvrage est la présentation des sources archivistiques et de la bibliographie concernant le sujet qui occupe près de la moitié du texte.

Aussi la collection, si elle est menée à bien, devrait constituer, à terme, un remarquable outil à disposition des chercheurs en sciences sociales sur l'agriculture de la France.

On ne peut que souhaiter la mobilisation des chercheurs ruralistes sur les autres départements afin que cet ambitieux projet aboutisse. L'aide de la fondation Xavier Bernard assure financièrement la publication de ces ouvrages, ce n'est pas mince.

Jean RENARD

\section{Charlotte Prieur, Louis Dupont (dir.), 2012. Les espaces de masculinités, Revue Géographie et Cultures, $\mathrm{n}^{\circ} 83$, Paris, L'Harmattan.}

Les travaux sur les constructions de genre et les sexualités occupent une place certes croissante mais encore faible dans la géographie française. Cela est tout particulièrement vrai pour les masculinités. Ce numéro de la revue Géographie et cultures dirigé par Charlotte Prieur et Louis Dupont vient donc combler un vide. Il réunit 7 textes ainsi qu'un fort utile ensemble regroupant des recensions d'ouvrages et la présentation de deux films (Laurence Anyways et Skins) portant sur les sexualités et les corps dans les espaces. Le premier texte (Charlotte Prieur et Louis Dupont. État de l'art : géographies et masculinités) et le dernier (Karine Kaplan. Les géographies des sexualités et la géographie française peuvent-elles faire bon ménage? Une revue critique des géographies des sexualités anglophones) rendent compte de la richesse des apports heuristiques des travaux de géographes anglophones et de l'intensité des débats théoriques et idéologiques ayant animé ce champ d'étude des sexualités né au début des années 1980.

Les trois grands ensembles de questionnements ou d'orientations de recherche qui structurent ces travaux s'inscrivent respectivement dans les études gaies, les études féministes, les études queer. Si les deux premiers se rejoignent dans l'analyse des dynamiques spatiales comme produit d'un système à la fois capitaliste et patriarcal, tous convergent dans la déconstruction des catégories préétablies. Les sexualités sont dès lors pensées comme «sys- 